\title{
Hemostatic Effect of the Nhi Chi Thang in Patients with Cystitis Bleed after Radiotherapy of Cervical Cancer
}

\author{
Phạm Hồng Vân ${ }^{1 *}$, Nguyễn Bội Hưong ${ }^{2}$ and Vũ Nam² \\ ${ }^{1}$ National Hospital of Acupuncture, Hanoi, Vietnam \\ ${ }^{2}$ Hospital of Traditonal Medecine, Vietnam
}

*Corresponding author: Pham Hong Van, National Hospital of Acupuncture, Hanoi, Vietnam

ARTICLE INFO

Received: 蔧 May 01, 2020

Published: May 18, 2020

Citation: Phạm Hồng Vân, Nguyễn Bội Hưong, Vũ Nam. Hemostatic Effect of the Nhi Chi Thang in Patients with Cystitis Bleed after Radiotherapy of Cervical Cancer. Biomed J Sci \& Tech Res 27(4)-2020. BJSTR. MS.ID.004547.

Keywords: Nhị chỉ thang; Cystitis; Radiation Therapy of Cervical Cancer

\section{Abstract}

Objective: To evaluation of hemostatic effects of the "Nhi chỉ thang" in patients with cystitis bleed after radiotherapy of cervical cancer.

Subjects and Methods: 40 patients after radiotherapy of cervical cancer, appeared grade 1, 2, 3 bleeding cystitis according to the classification of American Cancer Society (RTOG) in oral therapy take the decoction "Nhi only thang" packed in bags of $200 \mathrm{ml} \times 1$ bag/time x 2 times/day x 28 days.

Result: The "Nhi chỉ thang" had a reducing effect the number of blood urination in 24 hours, reduced the amount of blood in the urine, reduced the number of red blood cells in the urine, reduced the degree of bladder damage on the endoscopic bladder according to the RTOG, $(\mathrm{p}<0.05)$.

Conclusion: The "Nhị chỉ thang" has the effect of improving the situation of bleeding in the bladder in patients with cystitis bleed after radiation treatment of cervical cancer.

\section{Introduction}

Cervical cancer is one of the most common cancers in women, especially in their 30 years of age and older. According to data from the International cancer research organization, cervical cancer accounts for about $7.9 \%$ of all newly diagnosed cancers accounting for $7.5 \%$ of all cancer deaths among women. All around the world. In Vietnam, in 2012, 528,000 new cancer cases were diagnosed, and 266,000 women died from the disease [1,2]. Radiation therapy is one of the main ways to treat cancer. Radiation therapy may be indicated for radical or in combination with other methods (surgical, medical) or symptomatic treatment. There are many side effects and complications that can occur during radiation therapy. Radiation does not only affect tumors but also has an uncontrolled part of the impact around the radiation site, and bleed cystitis is one of the later complications after cervical cancer treated with radiotherapy $[1,3]$. "Nhi chi thang" is the traditional herbal remedies, origin from ancient remedy "Quy ty thang" has been proven to reduce pain (pain blocked) and stop bleeding (blood blocked), these are the two main symptoms that directly affect to the lives of patients such as reduced quality of life, reduced health
... in patients with cervical cancer receiving radiation. The study was conducted with the goal of evaluating the effects of the drug "Nhi chi thang" in patients with cystitis bleed after radiotherapy of cervical cancer.

\section{Materials and Methods}

\section{Subjects of the Study}

Patients with cystitis bleed after radiation treatment of cervical cancer grade I, II, III, according to the classification of the American Association for Radiotherapy [1,3]. Patients voluntarily participate in the study and receive inpatient treatment at the Department of Cancer Control and Treatment - National Hospital of Traditional Medicine.

The composition of "Nhi chi thang" [4-6]:

a) Codonopsis pilosula: $12 \mathrm{~g}$

b) Astragalus membranaceus: $16 \mathrm{~g}$

c) Rhizoma atrclylodis macrocephalae: $12 \mathrm{~g}$ 
d) Angelica sinensis: $12 \mathrm{~g}$

e) Dimocarpus longan: $12 \mathrm{~g}$

f) Glycyrrhiza uralensis: $8 \mathrm{~g}$

g) Zizyphus jujuba Lamk: 10g

h) Sophora japonica Linn: $10 \mathrm{~g}$

i) Lonicera japonica Thumb: $12 \mathrm{~g}$

j) Hedyotis diffusa: $10 \mathrm{~g}$

k) 11.Fibraurea tinctoria Lour: $12 \mathrm{~g}$

l) Rhiioma Imperatae: $12 \mathrm{~g}$

m) Cinnamomum tamala: $10 \mathrm{~g}$

n) Saussurea costus: $12 \mathrm{~g}$

o) Fallopia multiflora: $10 \mathrm{~g}$

p) Platycladus orientalis: $12 \mathrm{~g}$

Each box of herbal is extracted and divided into two packages containing $200 \mathrm{ml}$ of drug solution by a bag-packing machine at the Pharmacy Department, National Hospital of Traditional Medicine.

\section{Dosage}

Take two sachets (1 herbal box) / day, after eating, divided into two morning-afternoon times

\section{Treatment Course}

28 days

\section{Study Design}

Open clinical trial, comparing before- after treatment

\section{Sample Size}

40 patients diagnosed with stage II - III cervical cancer received radiation treatment at National Hospital $\mathrm{K}$ and appeared bleeding cystitis at level 1, 2, 3 according to the classification of Radiotherapy Association American cancer $[1,3]$.

\section{Excluded from the research:}

a. Patients with bladder cancer, who have metastases far have been treated with chemicals.

b. Patients with severe complications of the disease such as vaginal-bladder leakage, severe physical weakness.

c. Patients with coagulopathy, severe liver, and kidney diseases such as cirrhosis, renal failure, diabetics.

d. Patients self-quit or irregularly medication $\geq$ three times / time treatments, no cooperation during treatment.

\section{Clinical research criteria: Determined by monitoring, interviewing at different times:}
a) Starting treatment (D0),
b) Seven days after treatment (D7),
c) 14 days after treatment (D14),
d) After Treatment 21 days (D21),
e) After 28 days of treatment,
f) Finish treatment (D28),
g) Including: Times of urination in 24 hours,
h) Percentage of bloody urination in 24 hours,
i) Assessing the degree of bladder bleeding according to Droller's classification [7].

\section{Subclinical research criteria:}

Evaluation of the degree of bladder damage on cystoscopy done two times before and after treatment at the Department of Laboratory and Surgery, National Hospital of Traditional Medicine, is assessed according to criteria standard of American Association for Radiotherapy [7]. Determining the number of red blood cells in the urine by the total urine analysis test, divided into the levels:

a. Without red blood cells (-).

b. There are few red blood cells (+): corresponding to the test results is the trace, small.

c. Average red blood cell count (++): corresponds to moderate test results.

d. High red blood cell count (+++): corresponds to large test results.

\section{Results}

Tables (1-5).

\section{Discussion}

Regarding the effect of the remedy "Nhi chi thang" on signs of bladder bleeding in patients with cystitis bleeding after cervical cancer radiation treatment in clinical. Regarding the effect of reducing the number of times urinating blood in patients with cystitis bleed after radiotherapy of cervical cancer. According to the physiology of urine, people urinate and feeling of wanting to urinate because of bladder irritation. After radiation therapy, the damaged bladder mucosa becomes more sensitive and irritable, causing an urge to urinate. This causes the patient to pass urine several times and not much urine output. Another reason why patients urinate a lot is due to psychological anxiety, so during the night they do not 
need much sleep, the kidneys need to be constantly filtered, urine is always poured down, taking the time to fill up the urine in the bladder reduced and sick multiply urinating [1,8-10]. The results of the study presented in Tables $1 \& 2$ show that the hemostatic effect of the remedy is most evident from the $21^{\text {st }}$ day of treatment

Table 1: Change in frequency of urination in 24 hours $(n=40)$. $(\mathrm{p}<0.05)$. At the end of the course of 28 treatments, one patient $(2.5 \%)$ had 7 to 10 times a day, 34 patients (85\%) had 11 to 15 times of urination, and still, $12.5 \%$ of patients had the number of times urinating 16 to 19 times/day.

\begin{tabular}{|c|c|c|c|c|c|c|c|c|}
\hline \multirow{2}{*}{$\begin{array}{c}\begin{array}{c}\text { Number of } \\
\text { urination }\end{array} \\
\text { Time } \\
\end{array}$} & \multicolumn{2}{|c|}{$7-10$} & \multicolumn{2}{|c|}{$11-15$} & \multicolumn{2}{|c|}{$16-19$} & \multicolumn{2}{|c|}{$\geq 20$} \\
\hline & $\mathbf{n}$ & $\%$ & $\mathbf{n}$ & $\%$ & $\mathbf{n}$ & $\%$ & $\mathbf{n}$ & $\%$ \\
\hline $\mathrm{D}_{0}(1)$ & 0 & 0 & 11 & 27,5 & 23 & 57,5 & 6 & 15 \\
\hline $\mathrm{D}_{7}(2)$ & 0 & 0 & 15 & 37,5 & 22 & 55 & 3 & 7,5 \\
\hline $\mathrm{D}_{14}(3)$ & 0 & 0 & 23 & 57,5 & 15 & 35,7 & 2 & 5 \\
\hline $\mathrm{D}_{21}(4)$ & 0 & 0 & 28 & 70 & 12 & 30 & 0 & 0 \\
\hline $\mathrm{D}_{28}(5)$ & 1 & 2,5 & 34 & 85 & 5 & 12,5 & 0 & 0 \\
\hline $\mathrm{p}$ & \multicolumn{2}{|c|}{$\begin{array}{c}\mathrm{p}_{1-2,3,4}>0,05 \\
\mathrm{p}_{1-5}<0,05\end{array}$} & \multicolumn{2}{|c|}{$\begin{array}{c}\mathrm{p}_{1-2}>0,05 \\
\mathrm{p}_{1-3,4}<0,05 \\
\mathrm{p}_{1-5}<0,01\end{array}$} & \multicolumn{2}{|c|}{$\begin{array}{c}\mathrm{p}_{1-2}>0,05 \\
\mathrm{p}_{1-3,4}<0,05 \\
\mathrm{p}_{1-5}<0,01\end{array}$} & \multicolumn{2}{|c|}{$\begin{array}{c}\mathrm{p}_{1-2}<0,05 \\
\mathrm{p}_{1-3,4,5}<0,01\end{array}$} \\
\hline
\end{tabular}

Comment: The difference of 24-hour urination in patients before and after treatment was statistically significant with $\mathrm{p}<0.05$ and $\mathrm{p}$ $<0.01$.

Table 2: Changes in the frequency of urination with blood in 24 hours $(n=40)$.

\begin{tabular}{|c|c|c|c|c|c|c|c|c|}
\hline \multirow{2}{*}{$\begin{array}{c}\begin{array}{c}\text { Number of urination } \\
\text { with blood }\end{array} \\
\text { Time }\end{array}$} & \multicolumn{2}{|c|}{$0 \%$} & \multicolumn{2}{|c|}{$<50 \%$} & \multicolumn{2}{|c|}{$50 \%-70 \%$} & \multicolumn{2}{|c|}{$\geq 70 \%$} \\
\hline & $\mathbf{n}$ & $\%$ & $\mathbf{n}$ & $\%$ & $\mathbf{n}$ & $\%$ & $\mathbf{n}$ & $\%$ \\
\hline $\mathrm{D}_{0}(1)$ & 0 & 0 & 13 & 32,5 & 18 & 45 & 9 & 22,5 \\
\hline $\mathrm{D}_{7}(2)$ & 2 & 5 & 17 & 42,5 & 17 & 42,5 & 4 & 10 \\
\hline$D_{14}(3)$ & 4 & 10 & 20 & 50 & 13 & 32,5 & 3 & 7,5 \\
\hline $\mathrm{D}_{21}(4)$ & 5 & 12,5 & 27 & 67,5 & 7 & 17,5 & 1 & 2,5 \\
\hline $\mathrm{D}_{28}(5)$ & 7 & 17,5 & 27 & 67,5 & 6 & 15 & 0 & 0 \\
\hline $\mathrm{p}$ & \multicolumn{2}{|c|}{$\mathrm{p}_{1-2,3,4,5}<0,05$} & \multicolumn{2}{|c|}{$\begin{array}{l}\mathrm{p}_{1-2,3}<0,05 \\
\mathrm{p}_{1-4,5}<0,01\end{array}$} & \multicolumn{2}{|c|}{$\begin{array}{l}\mathrm{p}_{1-2}>0,05 \\
\mathrm{p}_{1-3}<0,05 \\
\mathrm{p}_{1-4,5}<0,01\end{array}$} & \multicolumn{2}{|c|}{$\mathrm{p}_{1-2,3,4,5}<0,01$} \\
\hline
\end{tabular}

Comment: At the start of treatment (D0), $100 \%$ of the patients had blood in their urine, of which 11 patients (27.5\%) had blood urination above $70 \%$ of the time per day.

After 28 days of treatment (D28), no patients had more than $70 \%$ of their urine peeing in 24 hours. $67.5 \%$ of patients urinate blood less than $50 \%$ of urination in 24 hours. 7 patients $(17.5 \%)$ did not urinate blood $(p<0.05$ and $p<0.01)$.

Regarding the number of times the urine saw blood, research results in Table 3 showed that, before taking the drug, there were 11 patients with blood urination on $70 \%$ of the time urinating in 24 hours; 16 patients urinated with blood urination between $50 \%$ and $70 \%$ of the time, and 13 patients with blood urination found less than $50 \%$ of the total time they urinated. At the end of treatment, seven patients no longer urinated blood, 27 patients urinated with blood less than $50 \%$ of the total time of urination, six patients with blood urination from $50 \%$ to $70 \%$ of times urinating $(\mathrm{p}<0.05)$. Regarding the effect of reducing the level of bladder bleeding in patients with cystitis bleed after radiotherapy of cervical cancer according to Droller's standards: For normal people, when there is bleeding, the body's anticoagulant mechanism is activated to create blood clots in the veins that block the bleeding location so that blood does not flow out of the vessels. In patients with cervical cancer treated with radiation therapy, the radiation causes the vascular wall to become fibrous, when there is bleeding, this blood clot is unstable, easily sloughing due to bladder spasms. When large amounts of blood flow are not eliminated in time, they can collect to form larger blood clots, which can sometimes partially peel off, even plaque-causing patients to naturally urinate. Blood clot or urinary retention caused by blood clots that block the urinary tract. The greater the amount of blood in the urine, the greater the number of times the person urinates blood in the urine, the greater the degree of bleeding in the bladder and the longer the bleeding period, the more severe the degree of illness $[7,11,12]$. 
Table 3: Change the level of bladder bleeding according to Droller standards $(n=40)$.

\begin{tabular}{|c|c|c|c|c|c|c|c|c|c|c|}
\hline \multirow{2}{*}{$\begin{array}{c}\text { Degree } \\
\text { Time }\end{array}$} & \multicolumn{2}{|c|}{ Degree 0} & \multicolumn{2}{|c|}{ Degree 1} & \multicolumn{2}{|c|}{ Degree 2} & \multicolumn{2}{|c|}{ Degree 3} & \multicolumn{2}{|c|}{ Degree 4} \\
\hline & $\mathbf{n}$ & $\%$ & $\mathbf{n}$ & $\%$ & $\mathbf{n}$ & $\%$ & $\mathbf{n}$ & $\%$ & $\mathbf{n}$ & $\%$ \\
\hline $\mathrm{D}_{0}(1)$ & 0 & 0 & 0 & 0 & 14 & 35 & 16 & 40 & 10 & 25 \\
\hline $\mathrm{D}_{7}(2)$ & 0 & 0 & 1 & 2,5 & 17 & 42,5 & 14 & 35 & 8 & 20 \\
\hline $\mathrm{D}_{14}(3)$ & 0 & 0 & 1 & 2,5 & 21 & 52,5 & 14 & 35 & 4 & 10 \\
\hline $\mathrm{D}_{21}(4)$ & 0 & 0 & 2 & 5 & 24 & 60 & 13 & 32,5 & 1 & 2,5 \\
\hline $\mathrm{D}_{28}(5)$ & 0 & 0 & 2 & 5 & 26 & 65 & 12 & 30 & 0 & 0 \\
\hline $\mathrm{p}$ & \multicolumn{2}{|c|}{$\mathrm{p}_{1-2,3,4,5}>0,05$} & \multicolumn{2}{|c|}{$\mathrm{p}_{1-2,3,4,5}<0,05$} & \multicolumn{2}{|c|}{$\begin{array}{c}\mathrm{p}_{1-2}<0,05 \\
\mathrm{p}_{1-3,4,5}<0,01\end{array}$} & \multicolumn{2}{|c|}{$\mathrm{p}_{1-2,3,4,5}<0,05$} & \multicolumn{2}{|c|}{$\begin{array}{c}\mathrm{p}_{1-2}<0,05 \\
\mathrm{p}_{1-3,4,5}<0,01\end{array}$} \\
\hline
\end{tabular}

Comments: At the time before treatment, $100 \%$ of patients had gross hematuria at 3, 3, 4 levels. The degree of bleeding in patients decreased significantly after the 21st day of treatment ( $p<0.05$ and $p<0.01$ ).

At the time of pre-treatment, $100 \%$ of the patients had gross hematuria at three different levels. At the end of the 28-day course of treatment, only $30 \%$ of patients had mass hematuria. $65 \%$ of patients with microscopic hematuria sometimes had small clots, but the amount was negligible and $5 \%$ of patients. There was no blood in the urine $(\mathrm{p}<0.05)$. According to the conception of traditional medicine, bleed cystitis is a disease of blood, excessive heat in the bladder impact blood, and blood goes the wrong way; in combination with spleen qi deficiency, qi cannot control blood, cannot stores blood causing hematuria. In "Huyet Chung luan" (Blood discussing symptoms), Duong Ton Hai wrote: "Blood was born in the fire heart but spilled down in the liver, Qi was born in the kidneys that came up to lung but manipulated by the spleen; two organs water - fire is belonging to prenatal, the pregnant woman then prenatal creating postnatal, so the two organs water - fire are waiting in the spleen. The nutritional qi gets into the spleen, spleen creates nutrients and brought up the fire heart, fire heart turned into fire, that is called blood. So cure blood must cure the spleen to master. The remedy "Nhi chi thang" has the effect of the spleen, thus strengthening the effect of the spleen system to regulate the spleen (which regulates the movement of blood) from which to stop the blood $[4,13,14]$.
The remedy used clear heat dry dampness, relieve toxicity herbs such as Lonicera japonica Thum, Hedyotis diffusa, Fibraurea tinctoria Lour, Rhiioma Imperatae and other sedative drugs such as Dimocarpus longan, Zizyphus jujube Lamk has been removed stimulation agents in the bladder area, thereby reducing the frequency of urination per day of the patient. The cool blood, stop bleeding herbs such as Rhizoma Imperatae, Platycladus orientalis eliminating toxic heat should have a hemostatic effect. The hemostatic herbs in the remedy are all black roast in the sense of regulating the kidney to increase the hemostatic effect of the lower part of the bladder. Among the above hemostatic herbs, especially the Rhiioma Imperatae is a herb used to fight inflammation, stop the blooding, fight urinary tract infections according to traditional medicine. The herbs in the remedy work together to create the hemostatic effect of the remedy $[4,14,15]$. The above results indirectly show that damaged cells in the bladder area are gradually restored, and to begin restoring bladder excretion function after radiotherapy requires a minimum of 4 weeks of treatment with the remedy "Nhi chi thang." The effect of the remedy "Nhi chi thang" on the image of cystoscopy in patients with cystitis bleeds after cervical cancer radiotherapy (Figure 1).
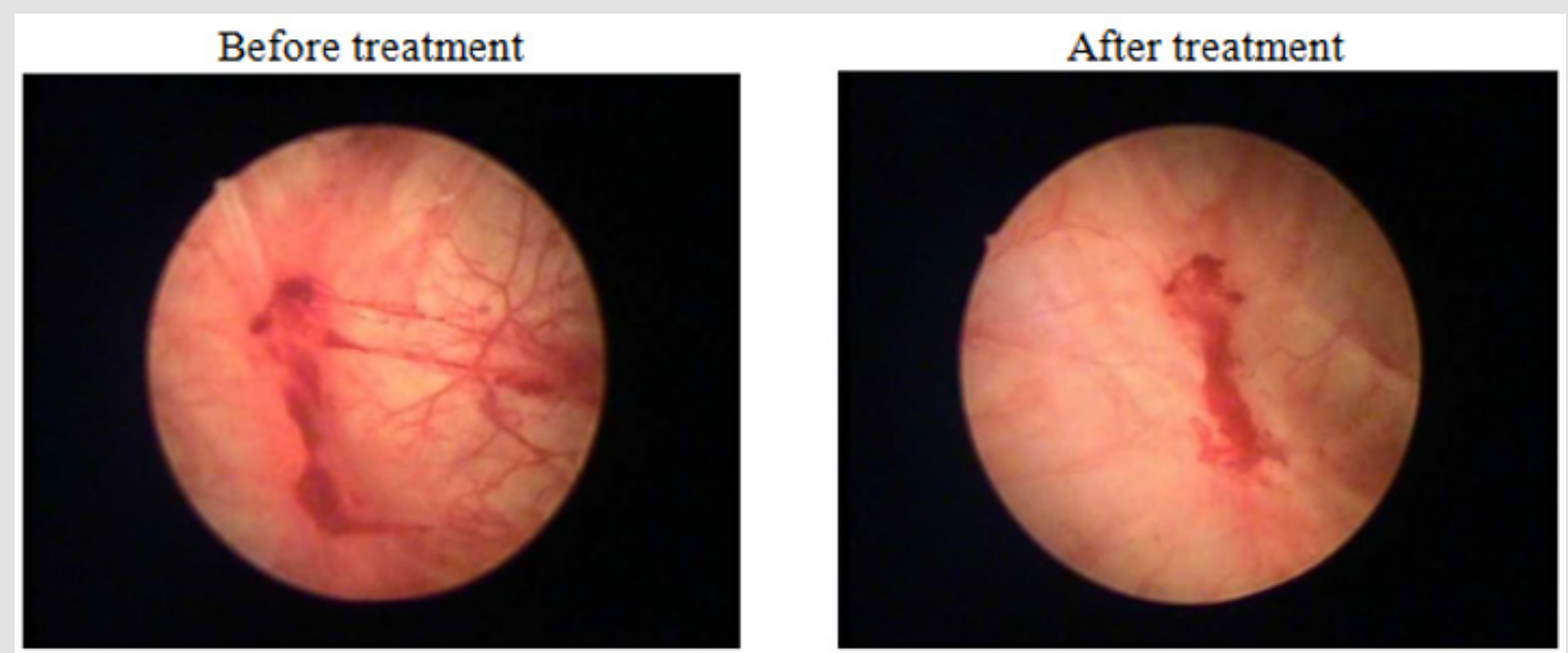

Figure 1: Cystoscopy picture of N.T.M.T patients before and after treatment. 
Cystourethroscopy is a procedure that directly examines the image of the urethra (the anterior and posterior urethra), and the bladder is most commonly indicated in hematuria, gross hematuria (eye). Often visible and microscopic hematuria. Endoscopic imaging is the gold standard for diagnosis and evaluation of treatment results for post-radiation bleeding cysts [1,3]. Endoscopy of cystoscopy showed that, at time D0, there were $17 / 40$ (42.5\%) of patients with grade III cystitis, $22 / 40$ (55.0\%) of patients with grade II cystitis, only 1 in 40 (2.5\%) of patients with grade I. Cystitis. However, after 28 days of treatment, only $8 / 40$ (20\%) of patients with grade 3 and $24 / 40$ cystitis (60\%). Patients with grade 2 cystitis, and up to $8 / 40$ $(20 \%)$ patients with type 1 cystitis $(\mathrm{p}<0.05)$. Bleeding cystitis is a disease caused by the side effects of radiotherapy of sub-regional cancer. Under the action of radiation, cells of related organs (including the urinary system) are bombarded, injured, destroyed, causing disruption of physiological functions of organs, including inflammation. , bleeding at different levels $[7,12]$.

According to the concept of Traditional Medicine, cancer has the name "Nham Chung"; meaning rugged, jagged, hard as rocky mountains, described in ancient literature as "emerging like a mountain," "carved like a ravine," "jagged as a cliff," due to melancholy worry outrageous anger, willpower disorders spleen, gallbladder qi frustrated, stagnant blood qi that create disease $[13,14]$. The nutrition qi gets into the spleen. The spleen creates nutrients brought to the fire heart. The heart turns into fire, which is called blood. Should treat spleen blood to take control of the spleen". Thus, related to the pathology of blood here, there are organs of heart, liver, kidney, and spleen, in which the spleen plays an important role in regulating the function of the organs of heart, liver, kidney $[3,13,14]$. Effects of remedy "Nhi chi thang" on erythrocyte index in patients with cystitis bleed after radiotherapy of cervical cancer. The research results presented in Table 4 show that before treatment, $40 \%$ of patients had erythrocytes $(+++)$; $20 \%$ of patients have red blood cells $(++)$, and $40 \%$ of patients had red blood cells (+) At the end of treatment, $2 \%$ of patients had urinary red blood cells; $65 \%$ of patients have red blood cell (+); $20 \%$ of patients have red blood cells $(++)$; Only $10 \%$ of patients had erythrocyte $(+++),(p<0.05$ and $p<0.01)$. The result of reducing the number of red blood cells in the urine is scientific evidence, has quantified the hemostatic effect of the remedy "Nhi chi thang" in the treatment of clinical cystitis.

Table 4: Changes in the number of red blood cells in the urine $(n=40)$.

\begin{tabular}{|c|c|c|c|c|c|}
\hline Time of research & \multicolumn{2}{|c|}{ Before Treatment (1) } & \multicolumn{2}{|c|}{ After Treatment (2) } & \multirow{2}{*}{$\mathbf{p}_{1-2}$} \\
\hline Degree & $\mathbf{n}$ & $\%$ & $\mathbf{n}$ & $\%$ & \\
\hline Red blood cell (-) & 0 & 0 & 2 & 5 & \multirow{5}{*}{$<0,05$} \\
\hline Red blood cell (+) & 16 & 40 & 26 & 65 & \\
\hline Red blood cell $(++)$ & 8 & 20 & 8 & 20 & \\
\hline Red blood cell $(+++)$ & 16 & 40 & 4 & 10 & \\
\hline Total & 40 & $100 \%$ & 40 & $100 \%$ & \\
\hline
\end{tabular}

Comment: Before treatment, $40 \%$ of patients had red blood cells $(+++) ; 20 \%$ of patients have red blood cells $(++)$, and $40 \%$ of patients have red blood cells (+).

At the end of the treatment, $2 \%$ of the patients had negative erythrocytes; $65 \%$ of patients have red blood cell (+); $20 \%$ of patients have red blood cells (++); Only $10 \%$ of patients have RBC $(+++)$.

The difference in the number of red blood cells in the urine at the time before and after treatment was statistically significant with $\mathrm{p}$ $<0.05$.

Table 5: Change the degree of bleeding cystitis based on cystoscopy $(n=40)$.

\begin{tabular}{|c|c|c|c|c|c|}
\hline \multirow{2}{*}{ Degree } & \multicolumn{2}{|c|}{ Before treatment (1) } & \multicolumn{2}{c|}{ After treatment (2) } & Rate (\%) \\
\cline { 2 - 5 } & Number of patients & Rate (\%) & Number of patients & 20 \\
\hline Degree I & 1 & 2,5 & 8 & 60 \\
\hline Degree II & 22 & 55 & 24 & 20 \\
\hline Degree III & 17 & 42,5 & 8 & 0 \\
\hline Degree IV & 0 & 0 & 0 & 100 \\
\hline Total & 40 & 100 & 40 & $<05$ \\
\end{tabular}

Comment: At time D0, there were $17 / 40$ (42.5\%) patients with degree 3 cystitis, 22/40 (55.0\%) patients with degree 2 cystitis, only $1 / 40(2.5 \%)$ patients with degree I. Cystitis At the end of the 28-day course of treatment, only $8 / 40(20 \%)$ of patients with degree III cystitis, 24/40 (60\%) of patients with degree II cystitis, and up to 8/40 (20\%) ) patients with degree I. Cystitis The difference was statistically significant with $\mathrm{p}<0.05$. 
The remedy "Nhi chi thang" is derived from "Quy ty thang" is a traditional remedy, in the composition of the medicine "Nhi chi thang," there are herbs that have blood tonic effects such as Angelica Sinensis, Dimocarpus longan, Fallopia multiflora has a tonify spleen, nutria heart and sedative effect have been reduced by a number of herbs, so it has the effect of tonifying spleen, stimulating qi, blocked blood to stimulate more blood and reduce blood loss, increase enhance the function of the digestive organs, enhance the effect of spleen blood regimen. The remedies also have clear heat and relieve toxicity herbs such as Lonicera japonica Thumb, Hedyotis diffuse. The herbs of cool blood stop bleeding such as Platycladus orientalis, especially her Rhiioma Imperatae, is a medicine used to fight inflammation, stop the bladder, fight urinary tract inflammation (Table 5). Herbs that have different types of flavonoids have the effect of neutralizing free radicals, which are the cause of disease, thereby contributing to repairing damage at the cellular level, restoring texture as well as The function of the organs, including the bladder and the urinary system, are all black roast according to the traditional medicine's conception that the kidney meridians increase the hemostatic effect of the lower gastric region, the bladder creates the hemostatic effect on clinical $[3,5,6,14]$.

\section{Conclusion}

Study on the hemostatic effect of the remedy "Nhi chi thang" on 40 patients with cystitis bleed grade 1, 2, 3 according to the classification of the American Association for Radiotherapy after radiotherapy of cervical cancer in the course of treatment orally, $400 \mathrm{ml}$ of "Nhi chi thang" is divided into two doses in the 28-day course of therapy. The results of the study showed that the remedy "Nhi chi thang" helps to improve bleeding cystitis: Reduces the number of blood urination in 24 hours. After the 28-day course of treatment, $34 / 40$ patients with blood urination saw less than $50 \%$ of the total number of times they urinated in 24 hours and 0 patients with blood urination above $70 \%$ of the total number of times the urine saw blood in 24 hours. Reducing the amount of blood in the urine: No more patients urinate large blood clots after treatment, there are $28 / 70$ patients microscopic hematuria, general but no blood clot, reaching the rate of $70 \%$. Urine tests showed a decrease in the number of red blood cells in the urine $(p<0.05)$. We are reducing the degree of bladder damage on cystoscopy images according to the standards of the American Association for Radiotherapy.

\section{References}

1. (2012) Ministry of Health cervical cancer. Introducing some common cancers. Medical Publishing House pp. 198-199.

2. (2010) World Health Organization/ICO Information Center (HPV Information Center), Human Papilloma virus and Related Cancers in World, Summary Report, Data sccessed, WHO Press. Geneva, Switzerland.

3. EORTC (European Organization for Research and Treatment of Cancer); RTOG, Radiation Therapy Oncology Group.

4. Hoang Bao Chau (2006) Internal Medicine of Traditional Medicine, Medical Publishing House pp. 503-506.

5. (2009) Ministry of Health, Vietnam Pharmacopoeia ( $4^{\text {th }}$ Edn.), Medicine Publishing House, Hanoi.

6. Do Tat Loi (2004) Vietnamese medicinal plants and herbs. Medicine Publishing House.

7. Droller MJ, Saral R, Santos G (1982) Prevention of cyclophosphamideinduced hemorrhagic cystitis. Urology 20(3): 256-258.

8. Levenback C, Eifel PJ, Burke TW, Morris M, Gershenson DM (1994) Hemorrhagic cystitis following radiotherapy for stage Ib cancer of the cervix. Gynecol. Oncol 55(2): 206-210.

9. Alesawi AM, El-Hakim A, Zorn KC, Saad F (2014) Radiation-induced hemorrhagic cystitis, Curr Opin Support Palliat Care 8(3): 235-240.

10. Denton AS, Clarke, Maher J (2002) Non-surgical interventions for late radiation cystitis in patients who have received radical radiotherapy to the pelvis, Cochrane, Syst Rev (1): CD001773.

11. Tran Dang Ngoc Linh (2013) Radiotherapy effects in stage IIB-IIIB cervical cancer, $\mathrm{PhD}$ thesis PP. 120 .

12.Zwaans BM, Nicolai HG, Chancellor MB, Lamb LE (2016) Challenges and Opportunities in Radiation-induced Hemorrhagic Cystitis. Rev Urol 18(2): 57-65.

13. Ton Hai Street (1987) Blood testimony, Ho Chi Minh City Publishing House p. 6.

14. Tran Van Ky (2000) Oriental medicine for cancer treatment, Mui Ca Mau Publishing House pp. 16-40.

15. Nguyen Thi Ngoc Linh (2012) Assessing the therapeutic effect of the second drug only on patients with rectal inflammation bleeding after cervical cancer radiation. Thesis graduated resident doctor.
ISSN: 2574-1241

DOI: 10.26717/BJSTR.2020.27.004547

Phạm Hồng Vân. Biomed J Sci \& Tech Res

cC) This work is licensed under Creative Commons Attribution 4.0 License

Submission Link: https://biomedres.us/submit-manuscript.php

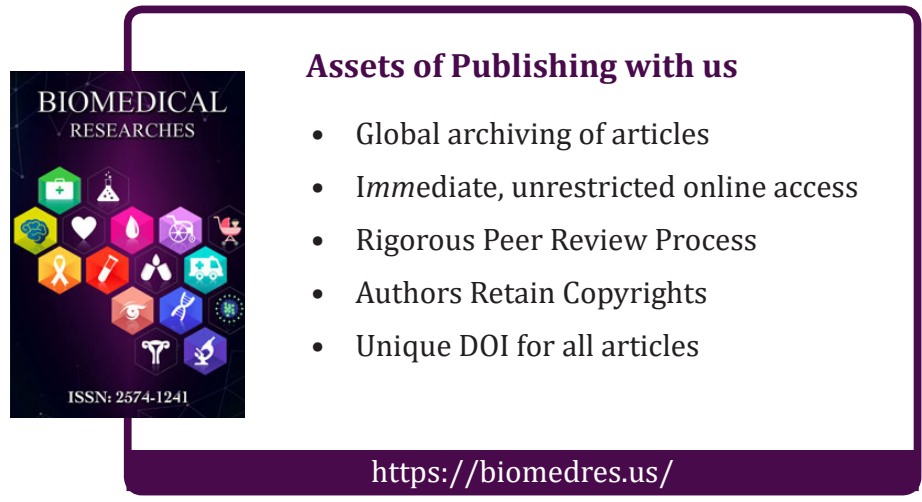

